\title{
High Temperature Corrosion in Gasifiers
}

\author{
Wate Bakker* \\ EPRI \\ 3412 Hillview Avenue \\ Palo Alto, CA 94304, USA
}

Received: September 2, 2002; Revised: September 4, 2002

\begin{abstract}
Several commercial scale coal gasification combined cycle power plants have been built and successfully operated during the last 5-10 years. Supporting research on materials of construction has been carried out for the last 20 years by EPRI and others. Emphasis was on metallic alloys for heat exchangers and other components in contact with hot corrosive gases at high temperatures. In this paper major high temperature corrosion mechanisms, materials performance in presently operating gasifiers and future research needs will be discussed.
\end{abstract}

Keywords: coal gasification, syngas coolers, sulfidation, downtime corrosion, stainless steel

\section{Introduction}

Intensive development of gasification technology has been carried out since the early seventies ${ }^{1,2,3}$. At present several commercial or nearly commercial scale coal gasification combined cycle plants are in operation worldwide. These include plants based on the Texaco and Dow processes in the USA, a plant based on the PRENF10 (Krupp-Koppers) process in Spain and a plant based on the Shell process in the Netherlands. All present plants include entrained slagging gasifiers and cold gas cleanup equipment. In this type of gasifier the fuel, coal, petroleum coke or heavy oil bottoms, are pulverized and fed to the gasifier in dry or slurry form. Gasification is carried out at very high temperatures, above the melting point of the mineral matter in the fuel, usually at $1300-1600^{\circ} \mathrm{C}$. The raw hot gas, consisting mainly of $\mathrm{CO}$ and $\mathrm{H}_{2}$, with $\mathrm{H}_{2} \mathrm{~S}$ as the major corrosive impurity, is cooled in syngas coolers and then water quenched to remove particulates and water soluble impurities such as $\mathrm{NH}_{3}$ and chlorides. After quenching, $\mathrm{H}_{2} \mathrm{~S}$ is removed in one of several commercially available gas purification systems. The purified gas is then fed to a gas turbine combined cycle plant for combustion and electricity generation. Figure 1 shows a schematic of such a plant, which is quite complex. Several corrosion and erosion problems have occurred in various plants, mostly at the pilot plant stage. These include coal slurry erosion and corrosion in feed systems, refractory corrosion and erosion in gasifiers, high temperature corrosion

*e-mail: wbakker@epri.com

Presented at the International Symposium on High Temperature Corrosion in Energy Related Systems, Angra dos Reis - RJ, September 2002. in syngas coolers and aqueous corrosion in down stream and gas purification equipment. Most of the problems found are not unique to gasifiers, but have been encountered elsewhere and have been resolved using existing technology. However high temperature corrosion in syngas coolers is unique to gasifiers, especially when coal is used as the fuel, due to interaction between various impurities present in coal.

For the above reasons and the fact that this conference is dedicated to high temperature corrosion, this paper will concentrate on high temperature corrosion in syngas coolers.

Details on operating conditions in syngas coolers are provided in References 1 and 7 . The composition of the raw syngas depends on the gasification process used and the fuel composition, especially its sulfur and chlorine content. The syngas composition of processes with water-coal slurry systems is typically (vol \%) $\mathrm{CO} 35-45, \mathrm{CO}_{2} 10-15, \mathrm{H}_{2} 27-30$, $\mathrm{H}_{2} \mathrm{O} 15-25, \mathrm{H}_{2} \mathrm{~S} 0.2-1.2$. $\mathrm{HCl} 50-500 \mathrm{ppm}$; for a dry fed gasifier the $\mathrm{CO}$ content of the gas is considerably higher 62-64\%, while the $\mathrm{CO}_{2}$ and $\mathrm{H}_{2} \mathrm{O}$ contents are generally less than $4 \%$. Thus the oxygen partial pressure $\left(\mathrm{PO}_{2}\right)$ of a syngas from slurry fed gasifier is considerably higher than that from a dry fed gasifier. However the syngas composition reflects the high temperature equilibrium composition at 1300 $1500{ }^{\circ} \mathrm{C}$, while the heat exchangers operate at $300-600{ }^{\circ} \mathrm{C}$. This makes it difficult to calculate $\mathrm{PO}_{2}$ and $\mathrm{PS}_{2}$ values, since 


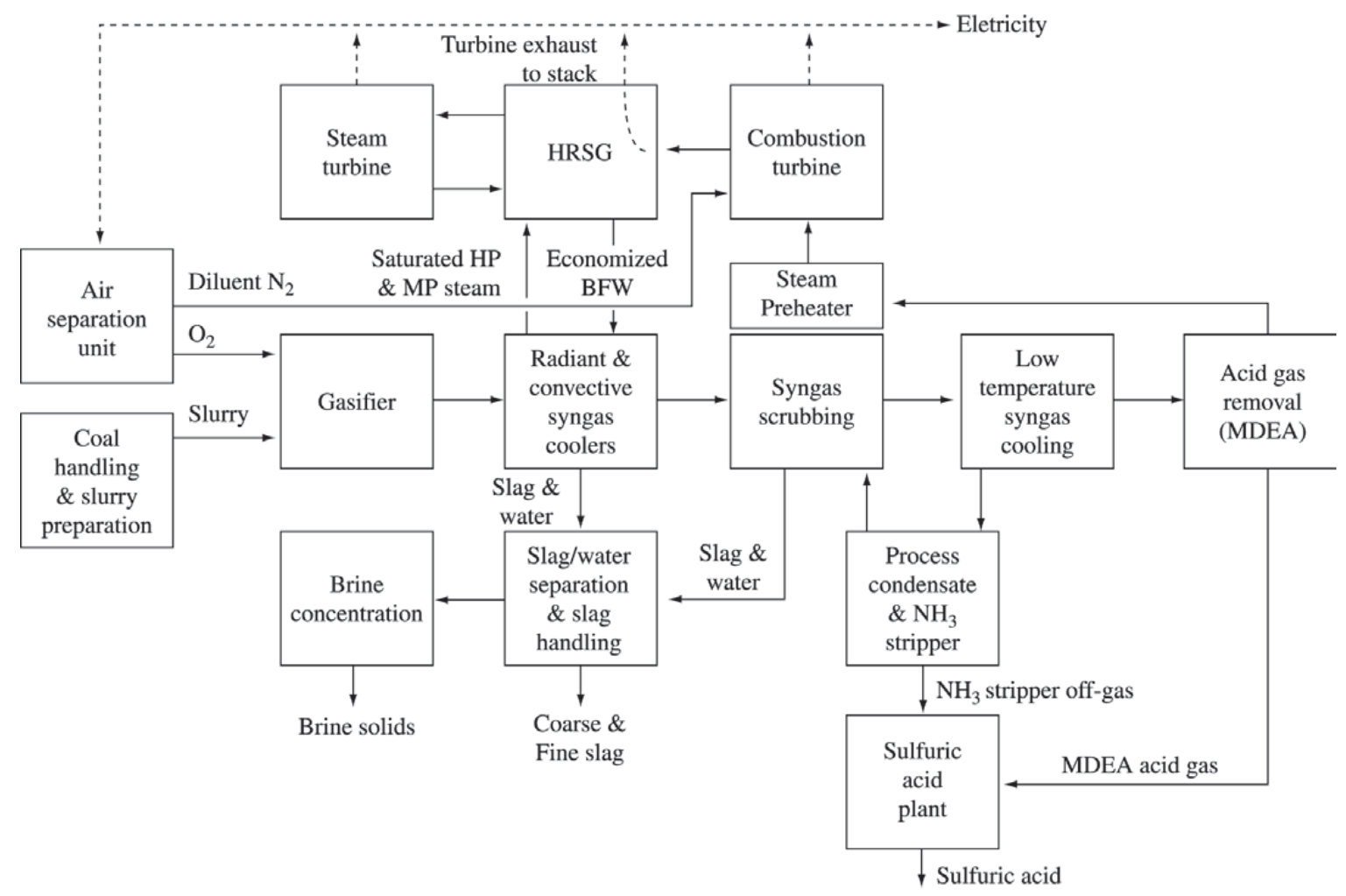

Figure 1. Process schematic for an integrated gasification combined cycle (IGCC) power plant.

the gases are not in equilibrium at the metal temperature ${ }^{1}$. Heat exchanger syngas operating temperatures in present gasifiers are generally less than $450{ }^{\circ} \mathrm{C}$, partly due to high temperature corrosion concerns and partially due to studies indicating that, with the present design, the use of higher heat exchanger temperatures is not cost effective.

\section{Corrosion Mechanism/Laboratory Studies}

The major corrosion mechanism in syngas coolers is sulfidation. Due to the low $\mathrm{PO}_{2}$ and relatively high $\mathrm{PS}_{2}$ of the raw syngas, the sulfidation rate of carbon and low alloy steels is too high to allow the use of these low cost materials. This is shown in Fig. 2, which contains information from laboratory as well as plant studies, with good agreement between the two. It is further observed that the corrosion rate of low alloy steels appears largely independent of the chlorine content of the coal. The plant data in Fig. 2 were obtained from coals or coal derived fuels with chlorine contents ranging from 0.05 to $0.3 \%$, resulting in $100-600 \mathrm{ppm}$ $\mathrm{HCl}$ in the syngas ${ }^{1}$. Laboratory tests confirm that $\mathrm{HCl}$ contents in this range do not increase corrosion rates, at least not under the highly reducing conditions present in gasifiers.

Due to the unacceptably high corrosion rates of low al-

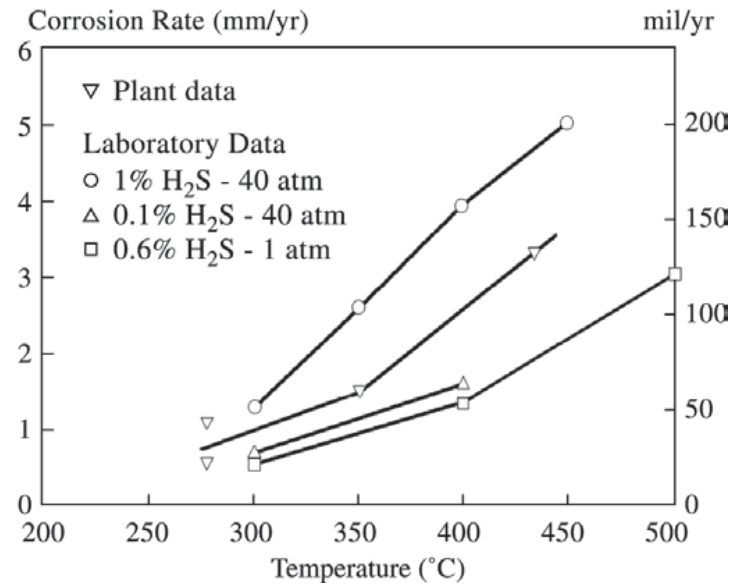

Figure 2. Corrosion of low alloy steels in syngas environments.

loy boiler steels, stainless steel heat exchanger tubes, coatings or claddings must be used to provide low corrosion rates. Extensive laboratory corrosion studies on both model and commercial alloys have been reported earlier ${ }^{1,4}$ and will be summarized here. All experiments were done under iso- 
thermal conditions. It was found that the corrosion rate of stainless steels containing $20 \%$ or more $\mathrm{Cr}$ with or without various minor alloying elements, such as $\mathrm{Si}, \mathrm{Al}$ and $\mathrm{Ti}$ did not simply increase with increasing sulfidation potential, as indicated by the $\mathrm{PS}_{2} / \mathrm{PO}_{2}$ ratio of the syngas, but also depended on the $\mathrm{HCl}$ content of the syngas, the presence of chlorides in deposits and alloy composition.

In the absence of $\mathrm{HCl}$ in the syngas, the corrosion loss indeed increases as a function of the $\mathrm{PS}_{2} / \mathrm{PO}_{2}$ ratio as shown in Fig. 3 for alloys $800(20 \mathrm{Cr}-32 \mathrm{Ni}-\mathrm{Fe}, \mathrm{Al}$, Ti) and 310 $(25 \mathrm{Cr}-20 \mathrm{Ni}-\mathrm{Fe})$. Corrosion rates are relatively low and parabolic reaction kinetics are usually observed ${ }^{5,6}$. SEM/EDS analysis indicates that at high $\mathrm{PS}_{2} / \mathrm{PO}_{2}$ ratios, a somewhat

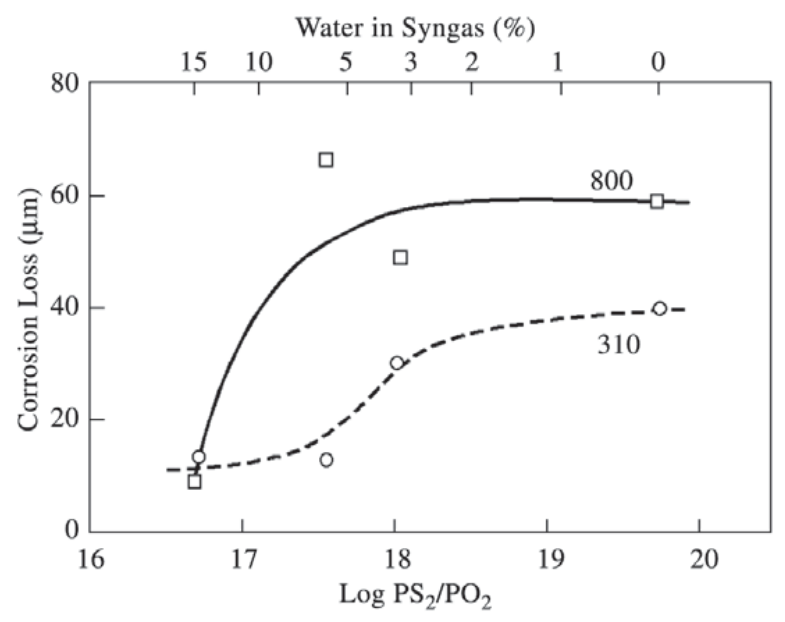

Figure 3. Corrosion losses of stainless steels as a function of $\mathrm{PS}_{2} /$ $\mathrm{PO}_{2}$ without $\mathrm{HCl}$ Laboratory test $540{ }^{\circ} \mathrm{C} 600 \mathrm{~h}$.

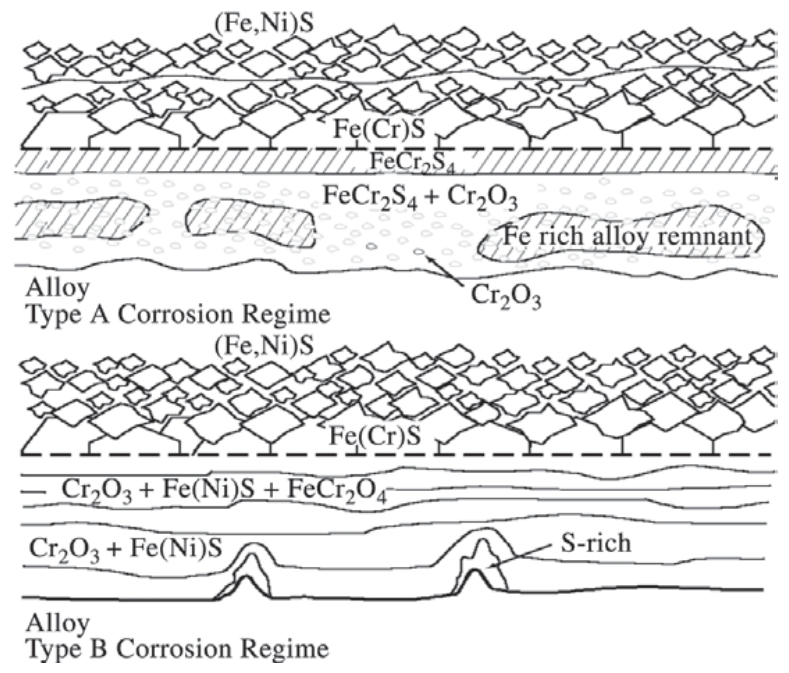

Figure 4. Schematic of scale morphology for Type A and B corrosion. protective $\mathrm{Fe} \mathrm{Cr}_{2} \mathrm{~S}_{4}$ spinel is formed. At lower $\mathrm{PS}_{2} / \mathrm{PO}_{2}$ ratios this layer gradually changes to $\mathrm{FeCr}_{2} \mathrm{O}_{4}$. Below the $\mathrm{FeCr}_{2} \mathrm{~S}_{6}$ layer an inward growing scale/precipitation zone is formed consisting of $\mathrm{FeCr}_{2}(\mathrm{~S}, \mathrm{O})_{4}$ spinels, $\mathrm{Cr}_{2} \mathrm{O}_{3}$ and iron rich alloy remnants. This corrosion mechanism is labeled Type A corrosion and is shown schematically in Fig. 4.

When $\mathrm{HCl}$ is present in the syngas the corrosion mechanism changes considerably as is shown in Fig. 5. Alloys with a relatively low chromium content such as alloy 800 now show a maximum corrosion rate at a $\log \mathrm{PS}_{2} / \mathrm{PO}_{2}$ ratio of about 18 , while alloys with a higher chromium content or similar oxide forming alloying elements such as $\mathrm{Al}$ or $\mathrm{Si}$ are relatively less affected by the addition of $\mathrm{HCl}$ to the gas. SEM/EDS analysis of Alloy 800 after exposure to a syngas with a $\log \mathrm{PS}_{2} / \mathrm{PO}_{2}$ ratio of about 18 and a $\mathrm{HCl}$ content of $400 \mathrm{ppm}$ indicated the absence of a protective $\mathrm{FeCr}_{2} \mathrm{~S}_{4}$ scale. An outward growing FeS rich scale is present on top of an inward growing porous $\mathrm{Cr}_{2} \mathrm{O}_{3}$ rich scale containing $\mathrm{Fe}(\mathrm{Ni}) \mathrm{S}$, which appears non protective. This corrosion mechanism is labeled Type B corrosion and is also shown schematically in Fig. 4. Further studies have shown that the onset of the less desirable Type B corrosion depends on the amount of oxide forming alloying elements in the alloy, the amount of $\mathrm{HCl}$ in the syngas and the presence of chlorides in deposits, which probably increases the $\mathrm{PCl}_{2}$ near the metal surface. For instance, the corrosion loss of stainless steel 310 after $164 \mathrm{~h}$ exposure to syngas with a $\log \mathrm{PS}_{2} / \mathrm{PO}_{2}$ ratio of 18.5 and $1200 \mathrm{ppm}$ is about $15 \mu \mathrm{m}$. However when a deposit containing $5 \%$ chloride is present the corrosion loss increases to $86 \mu \mathrm{m}$ and the corrosion mechanism changes from Type A to Type B as shown in Fig. 6.

Aqueous corrosion during downtime can further increase overall corrosion rates in the presence of chloride containing deposits. During downtime hygroscopic chlorides can migrate through cracks in the scale to the scale/metal inter-

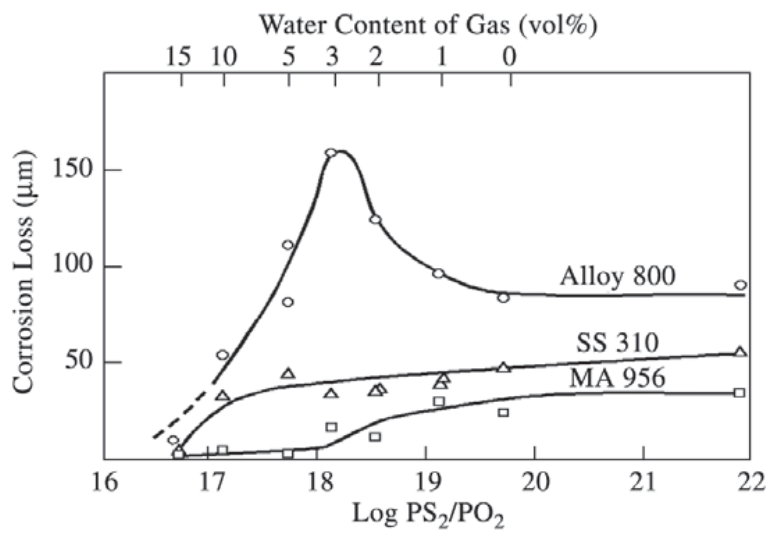

Figure 5. Corrosion loss of stainless steels as a function of $\mathrm{PS}_{2} /$ $\mathrm{PO}_{2}$ with $400 \mathrm{ppm} \mathrm{HCl}$. Laboratory test $600 \mathrm{~h}, 540{ }^{\circ} \mathrm{C}$. 


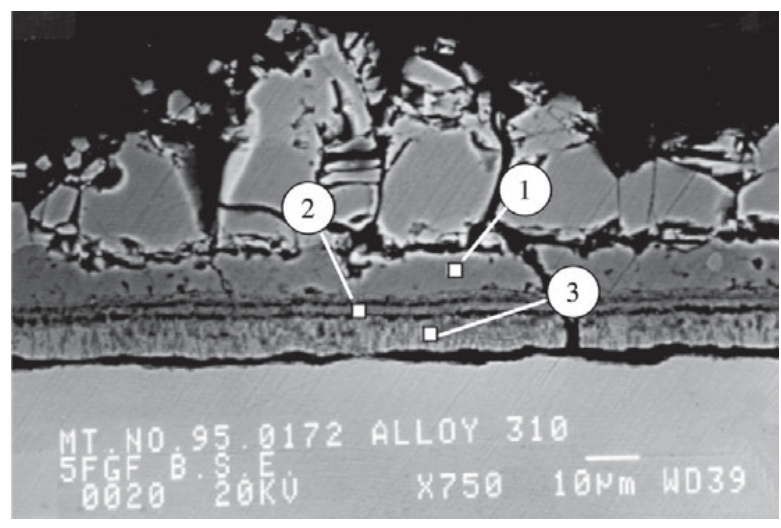

a)

Without coating corrosion loss $15 \mu \mathrm{m}$ EDS Analysis EDS Analysis (at\%)

\begin{tabular}{cccccccc}
\hline Area & $\mathrm{O}$ & $\mathrm{Si}$ & $\mathrm{S}$ & $\mathrm{Cr}$ & $\mathrm{Mn}$ & $\mathrm{Fe}$ & $\mathrm{Ni}$ \\
\hline 1 & 0 & n.d. & 58 & 28 & 3 & 11 & 0 \\
2 & 30 & 2 & 29 & 34 & 1 & 5 & 1 \\
3 & 29 & 2 & 3 & 30 & 0 & 33 & 2 \\
\hline
\end{tabular}

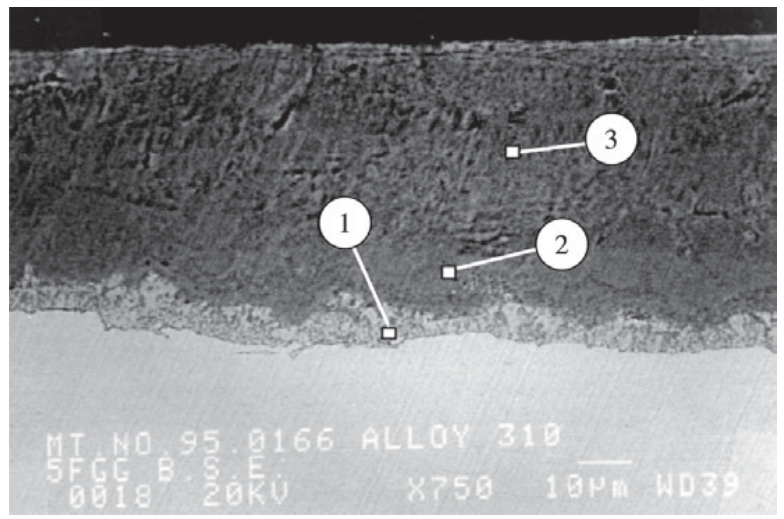

b)

With coating ( $5 \%$ chlorides) corrosion loss $86 \mu \mathrm{m}$ EDS Analysis EDS Analysis (at\%)

\begin{tabular}{cccccccc}
\hline Area & $\mathrm{O}$ & $\mathrm{Si}$ & $\mathrm{S}$ & $\mathrm{Cr}$ & $\mathrm{Mn}$ & $\mathrm{Fe}$ & $\mathrm{Ni}$ \\
\hline 1 & 37 & 2 & 4 & 33 & $<1$ & 23 & 1 \\
2 & 49 & 2 & 13 & 33 & 1 & 3 & 0 \\
3 & 49 & 2 & 10 & 31 & 1 & 6 & 1 \\
\hline
\end{tabular}

Figure 6. Corrosion of SS 310 in syngas with $1200 \mathrm{ppm} \mathrm{HCl}$ with and without coating containing $5 \%$ chloride.

face and form an $\mathrm{FeCl}_{3}$ rich layer beneath the scale. During heat up the $\mathrm{FeCl}_{3}$ layer causes spalling of the protective $\mathrm{Cr}_{2} \mathrm{O}_{3}$ rich scale and a new outward growing FeS rich scale and inward growing $\mathrm{Cr}_{2} \mathrm{O}_{3}$ rich scale is formed. This sequence repeats itself during each thermal cycle. Figure 7 shows the

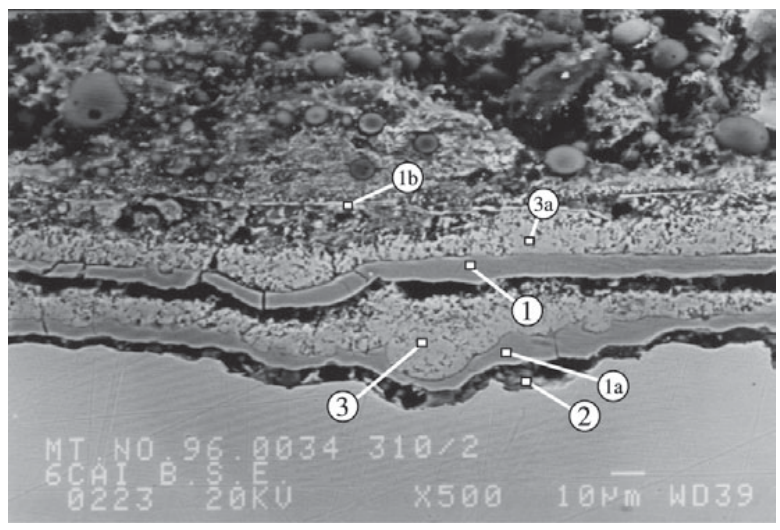

Figure 7. SEM image of SS310 after 3 high temperature/downtime corrosion cycles.

scale microstructure after three $200 \mathrm{~h}$ high temperature cycles and three $24 \mathrm{~h}$ downtime periods in humid air at $400{ }^{\circ} \mathrm{C}$.

From the laboratory experiments described above, it is clear that the high temperature corrosion of stainless steels in syngas environments is complex and not readily predictable from simple gas/solid reaction mechanisms, especially when $\mathrm{HCl}$ is present in the gas and/or chlorides in the deposit.

\section{Long Term Performance of Materials in Service}

Laboratory tests are usually conducted at atmospheric pressure under isothermal conditions for a few hundred to a few thousand hours. Materials and components of electric power plants should last at least $100,000 \mathrm{~h}$. In syngas coolers they are also exposed to elevated pressures, 40-60 atm, with significant thermal gradients. Thus laboratory tests are useful to determine corrosion mechanisms, and guide alloy selection, but are generally not suitable to predict actual corrosion rates. For this reason, EPRI has cooperated with several gasifier operators to obtain long term corrosion rate data in various pilot and commercial size gasification plants. Several materials have been exposed in various gasifiers for over $50,000 \mathrm{~h}^{7,8,9,10}$. Individual tests have ranged from 2000 to $17,000 \mathrm{~h}$, at temperatures ranging from $300-550{ }^{\circ} \mathrm{C}$.

In general, the corrosion mechanisms found in laboratory tests are also found in service, i.e., Type A corrosion under highly sulfidizing conditions at relatively low $\mathrm{HCl}$ levels, Type B corrosion under less sulfidizing conditions, at somewhat higher $\mathrm{HCl}$ levels and high rates of corrosion due to scale spallation when chlorides are present in the deposits, Fig. 8 shows an example of pitting and scale spallation of 310 stainless steel after 17,000 $\mathrm{h}$ exposure in a Texaco process gasification plant.

In the absence of scale spallation stainless steels con- 


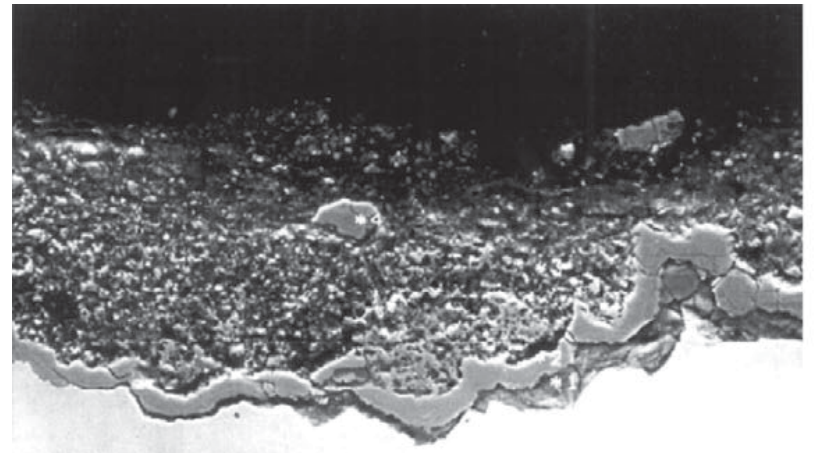

SAR $21.3 .1 \quad 00004$

$30 \mu \mathrm{m}$ a)

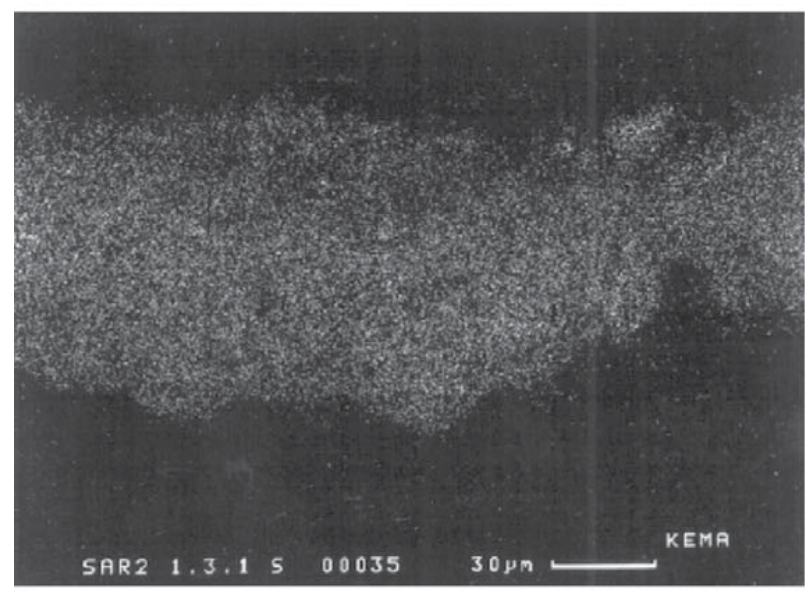

c)

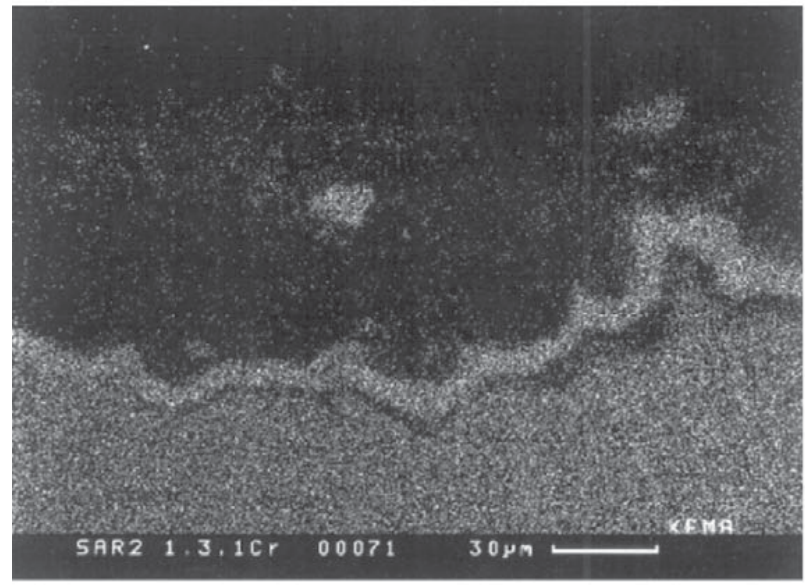

e)

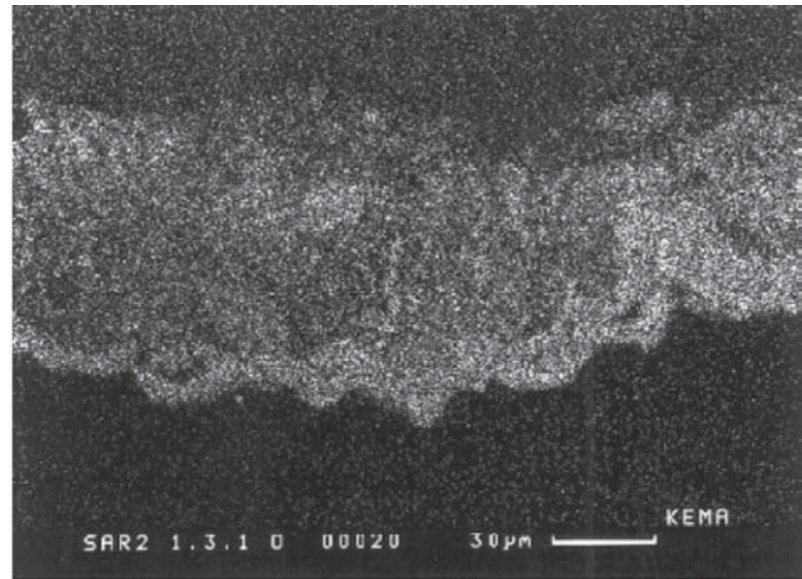

b)

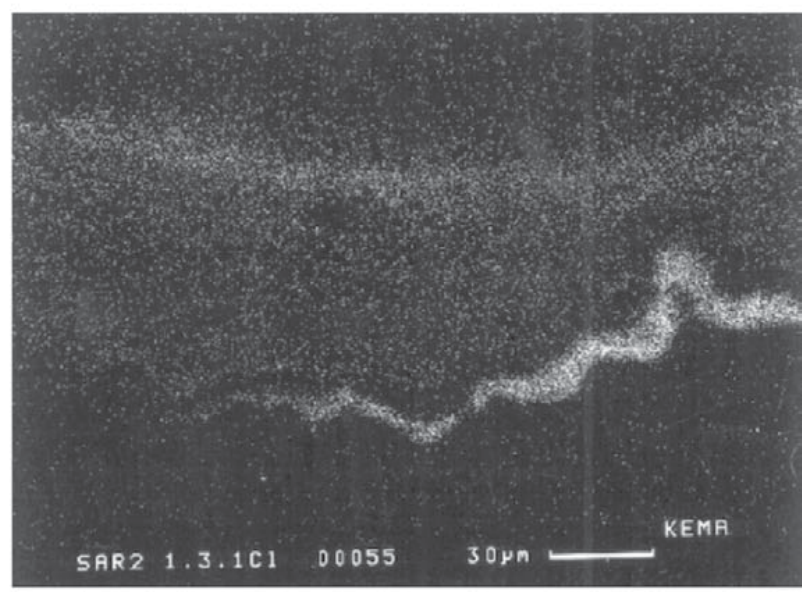

d)

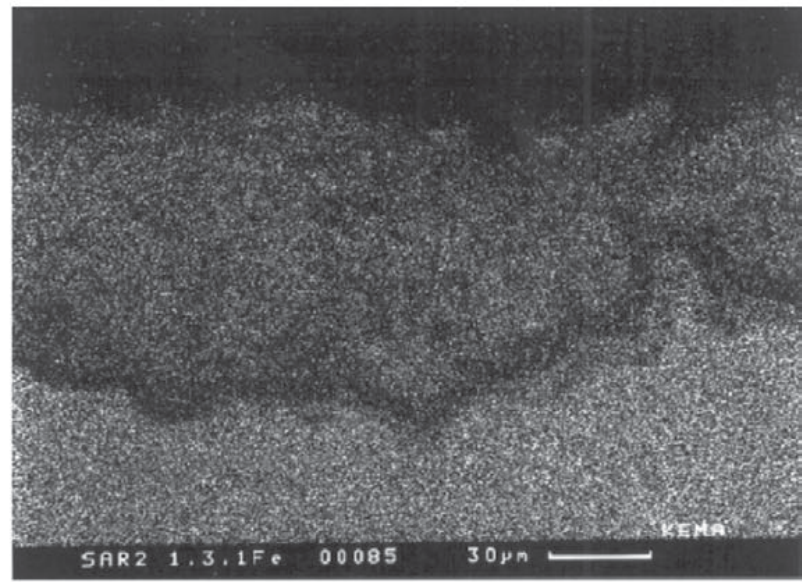

f)

Figure 8. SEM image and elemental maps of scale on 310 stainless steel after 17,000 h exposure in syngas cooler. 
taining at least $20 \% \mathrm{Cr}$ generally provide a satisfactory corrosion rate of about $0.1 \mathrm{~mm} / \mathrm{yr}$ or less in the $300-400{ }^{\circ} \mathrm{C}$ temperature range at which most heat exchanger surfaces in syngas coolers operate (Fig. 9). Corrosion mechanisms ranged from Type $\mathrm{B}$ corrosion for the lower $\mathrm{Cr}$ steels to Type A corrosion for steels with a higher $\mathrm{Cr}$ content such as 310 .

When scale spallation due to chloride migration to the scale/metal interface occurs, corrosion rates increase considerably even at relatively low temperatures. Figure 10 shows the corrosion loss of the 310 stainless steel of Fig. 8, as a function of time. The rate is linear and is about 0.25 $\mathrm{mm} / \mathrm{yr}$. Here a Mo containing alloy such as Sanicro 28 (27Cr, $32 \mathrm{Ni}, 3.5 \%, \mathrm{Cu})$ is a better choice because it has a parabolic corrosion rate, with less than $0.25 \mathrm{~mm}$ loss after 17,000 hr exposure. When the fuel gasified has very high $\mathrm{Cl}$ levels extremely high corrosion rates are possible. This is illustrated in Fig. 11, which gives the results of a $5500 \mathrm{~h}$ exposure tests in a gasifier using a fuel containing $0.2-0.5 \% \mathrm{Cl}$. Here stainless steels have completely unacceptable corrosion rates and Mo containing alloys, preferably with a high Ni content such as Alloy 625 are the only acceptable materials. It is interesting to note that Alloy 625 is also the preferred alloy for waste to energy plants, where chlorine is the major corrodent under oxidizing conditions ${ }^{11}$.

Field corrosion data from various gasifiers indicate that metal wastage rates experienced so far will not lead to catastrophically high corrosion rates. When sulfidation is the only or major corrosion mechanism (Type A corrosion) corrosion rates less than $0.1 \mathrm{~mm} / \mathrm{yr}$ are generally experienced for steels with $>20 \% \mathrm{Cr}$ at temperatures below $400{ }^{\circ} \mathrm{C}$. Thus Alloy 800 (20Cr, 32Ni, Al, Ti), which is code approved for boiler service would be an economical choice and is indeed frequently used. However when the $\mathrm{Cl}$ content of the fuel is somewhat higher and the syngas is less sulfidizing, Type B corrosion can lead to highly increased corrosion rates. Under these conditions Alloy 800 and especially the weld material used for this alloy, INCO $82(20 \mathrm{Cr}, \mathrm{Ni}, \mathrm{Nb})$ are less suitable and alloys with a higher $\mathrm{Cr}$ content are needed. 310 stainless steel has an adequate corrosion resistance, but is not approved for boiler service, due to potential waterside corrosion problems. Sanicro 28 is code approved and is also more resistant to $\mathrm{Cl}$ induced scale spallation. It is therefore the logical choice for application where Type B corrosion or scale spallation is likely.

In isothermal laboratory corrosion tests, scale spallation under $\mathrm{Cl}$ rich deposits is observed only in tests combining exposure at high temperature, with shorter periods of exposure to humid air (downtime corrosion). Similar scale spallation is also frequently found in service, but it also occurs when exposure to aqueous corrosion conditions is infrequent, i.e., when the plant operates continuously with only 1 or 2 shutdown year. Recently corrosion tests were carried out under thermal gradients to study waterwall corrosion in

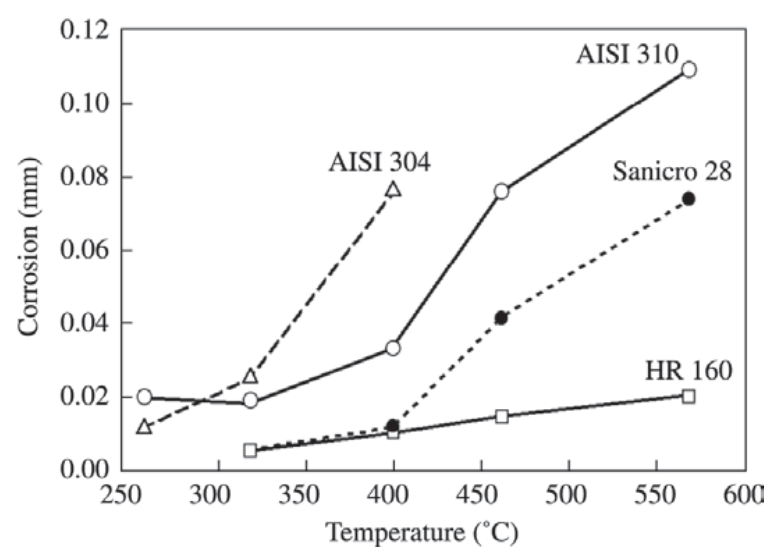

Figure 9. Corrosion loss of stainless steels after 2,000 h exposure in the PRENFLO demonstration plant.

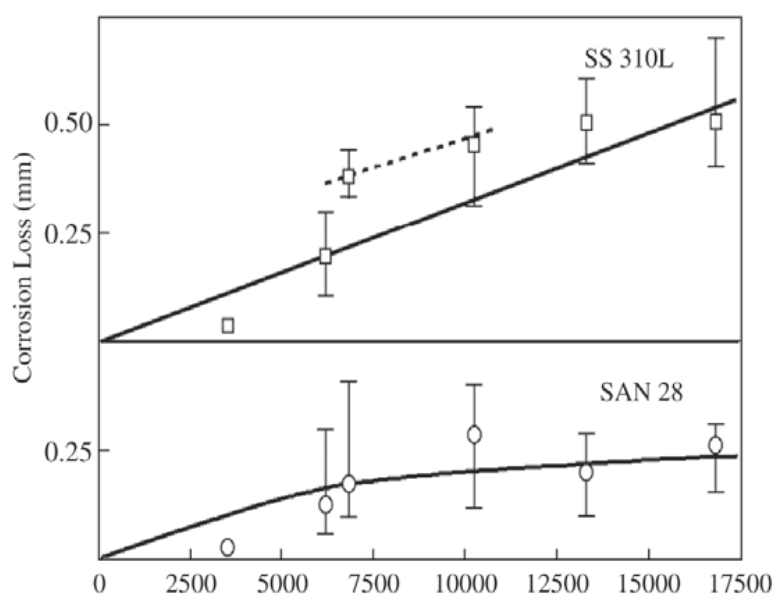

Figure 10. Corrosion of SS 310 and Alloy 28 during exposure in a syngas cooler At $390-420^{\circ} \mathrm{C}$.

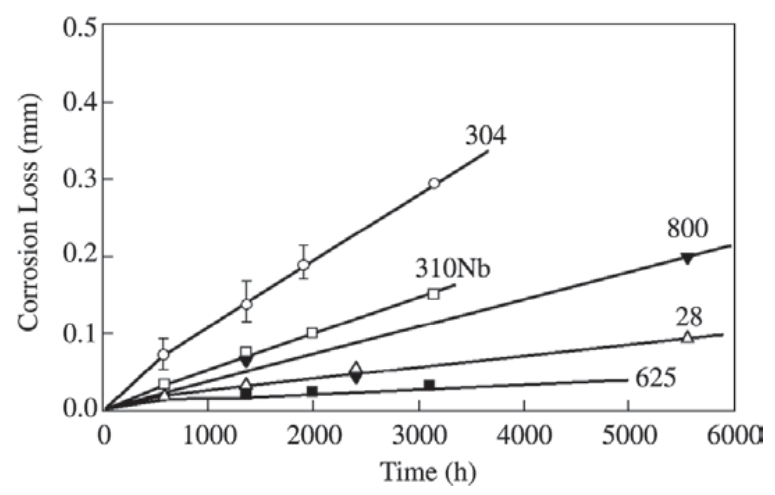

Figure 11. Corrosion losses of stainless steels and $\mathrm{Ni}$ alloys from a coal gasification Plant, gasifying coal residues with $0.2-0.5 \% \mathrm{Cl}$. 
boilers $^{12}$. It was found that chloride species in deposits can also move to the metal-scale interface and cause scale spallation when a thermal gradient is present, especially when the thermal gradient is steep enough to cause melting of the chloride mixture. Thus, we now believe that aqueous corrosion during downtime is not the only cause of scale spallation, but that thermal gradients in deposits may be a more likely culprit, especially in commercial gasifiers, where downtime is infrequent.

Finally it should be noted that all fuels used for present and future gasification plants can have dangerous $\mathrm{Cl}$ levels. Refinery wastes, petroleum coke and heavy oil bottoms have nominally low Cl levels. However "Phantom chlorides" have become a problem in refineries ${ }^{13}$. In one of our exposure tests using heavy fuel oil, nominally free of $\mathrm{Cl}$, spallation due to chlorine corrosion was also experienced. The chlorine content of most coal is relatively low $0.1 \%$ or less. However the resulting $\mathrm{HCl}$ levels during gasification are much higher than in boilers and chlorides are frequently found in heat exchanger deposits, when gasifying coals with $\mathrm{Cl}$ contents as low as $0.1 \%$.

\section{Conclusions}

1. Commercial scale gasification power plants have operated trouble free for long periods of time and using commercially available steels.

2. Corrosion losses due to high temperature sulfidation alone are generally low enough to provide acceptable long term service, especially when the $\mathrm{Cr}$ content is $20 \%$ or higher.

3. The presence of chloride rich deposits can cause scale spallation, resulting in accelerated corrosion. When this occurs common stainless steels have linear corrosion rates and Mo containing steels are preferred. They have more adherent scales and exhibit parabolic corrosion rates.

\section{References}

1. Bakker, W.T. Effect of Gasifier Environment on Materials Performance, Materials at High Temperatures 11 (14), p. 90, 1993.

2. Liere, J. van Present Status of Advanced Power Plants. Materials at High Temperatures 14 (2,3), p. 7, 1997.

3. Bakker, W.T. Present Status of Coal Gasification Technology, Proc. Materials for Coal Gasification, V. Hill, S. Dapkunas, W. Bakker, Ed., October 1987, ASM International, 1988.

4. Bakker, W.T. The Effect of Chlorine on Mixed Oxidant Corrosion of Stainless Steels, Mat. At High Temperature, v. 14, n. 3, p. 197, 1997.

5. Norton, J. et al., Proc. Heat Resistant Materials II, K. Natesan, P. Ganesan and G. Lai, eds., ASM International, p. $111,1995$.

6. John, R.C. et al., Materials at High Temperatures, 11(14), p. 124, 1993.

7. Bakker, W.T.; Stringer, J. Mixed Oxidant High Temperature corrosion in Gasifiers and Power Plants, Materials at High Temperature, v. 14, n. 2, p. 101, 1997.

8. Bakker, W.T.; Kip, J.B.M.; Schmitz, H.P. Materials at High Temperatures 11(1-4), p. 133, 1993.

9. Schellberg, W. et al., Materials at High Temperatures 14(2), p. 159, 1997.

10. Fahrion, M.E. Materials at High Temperatures, 11(14), p. 107, 1993.

11. Sorell, G. Materials at High Temperatures, 14 (2,3), p. 37, 1997.

12. Bakker, W.T.; Blough, J.E.; Seitz, W.; Kung, S.C. “The Effect of Deposits on Waterwall Corrosion" to be published in proc. Materials for Advanced Power Engineering, Liege, 2002.

13. Veasey, M.V. "Phantom Chlorides Create Real Problems for Refineries", Materials Performance, May 2002, p. 17-19, NACE International. 